\title{
Atendimento Educacional Especializado: planejamento e uso do recurso pedagógico
}

\author{
MANOEL OSMAR SEABRA JUNIOR \\ Universidade Estadual Paulista, Presidente Prudente, SP, Brasil
}

LONISE CAROLINE ZENGO DE LACERDA Universidade Estadual Paulista, Presidente Prudente, SP, Brasil

RESUMO

Analisar as contingências a que o professor do Atendimento Educacional Especializado está submetido ao realizar o desenvolvimento e aplicação dos recursos pedagógicos necessários aos estudantes da sala de recurso multifuncional foi o objetivo desta investigação. Utilizou-se roteiro de entrevista semiestruturada seguido por análise de conteúdo. Como base para a entrevista e escopo teórico, recorreu-se a um fluxograma com etapas para o desenvolvimento de recursos de tecnologia assistiva. Os resultados demonstraram que os professores realizam as etapas propostas pelo fluxograma, porém não se exaurem nelas, manifestando na prática docente preocupações em diferentes áreas, como o trabalho colaborativo, a invisibilidade do recurso de tecnologia assistiva, constante compreensão do universo do aluno e, principalmente, o acompanhamento do uso de recursos no ambiente escolar. Apresenta-se na conjuntura de ações convergência de conhecimentos teóricos, da práxis e da contextualização com a realidade.

PALAVRAS-CHAVE

tecnologia assistiva; recurso pedagógico; sala de recurso multifuncional. 


\title{
SPECIALIZED EDUCATIONAL ASSISTANCE: PLANNING AND USE OF PEDAGOGICAL RESOURCES
}

\begin{abstract}
The objective of this investigation was to analyze the constraints to which teachers of Specialized Educational Assistance are subject to when carrying out the development and use of pedagogical resources for students of multifunctional resource rooms. We used a semi-structured interview script followed by a content analysis. A flowchart illustrating the development of assistive technology resources served as a basis for the interviews and theoretical framework. The results showed that teachers followed the steps proposed by the flowchart, but they were not limited by it. The teachers expressed various concerns in their teaching practice, such as collaborative work, the "invisibility" of the assistive technology resources, continuous understanding of the universe of their students, and especially, monitoring of the use of resources in the school environment. Their actions show a convergence of theoretical knowledge, "praxis" and contextualization of reality.
\end{abstract}

KEYWORDS

assistive technology; pedagogical resources; multifunctional resource room.

\section{ATENDIMIENTO ESPECIALIZADO EN EDUCACIÓN: PLANIFICACIÓN Y USO DEL RECURSO PEDAGÓGICO}

\section{RESUMEN}

Analizar las contingencias a las que el profesor de Servicio Educativo Especialista está sometido al llevar a cabo el desarrollo y la aplicación de los recursos de enseñanza para estudiantes de la sala de recursos multifuncionales fue el objetivo de esta investigación. Se utilizó un guión de entrevista semiestructurada, seguido por análisis de contenido. Como base para la entrevista y alcance teórico, se utilizó un diagrama de flujo con las etapas para el desarrollo de los recursos de tecnología asistiva. Los resultados mostraron que los profesores llevan a cabo los pasos propuestos por el diagrama, pero no se exhalan en ellas, manifestando en la práctica de enseñanza preocupaciones en diferentes áreas, como el trabajo colaborativo, la invisibilidad del recurso de tecnología asistiva, el entendimiento constante del universo de alumno y, principalmente, el seguimiento del uso de los recursos en el ámbito escolar. Se presenta en la coyuntura de acciones de convergencia de conocimientos teóricos, de la praxis y de la contextualización con la realidad.

tecnología de asistencia; recursos educativos; aula de recursos multifuncionales. 


\section{INTRODUÇÃO}

No decorrer das últimas três décadas, o cenário educacional nacional sofreu mudanças importantes. Entre elas destacam-se as políticas para a educação especial na perspectiva da educação inclusiva, como: adequação curricular; política de acessibilidade na escola; análise acadêmico-científica das tecnologias de informação e comunicação (TIC); desenvolvimento de recursos de tecnologia assistiva (TA); implantação das salas de recursos multifuncionais (SRM); Plano de Atendimento Individualizado (PAI); formação continuada para professores de sala regular; salas de recursos e para gestores; entre outras ações que compreendem as inovações e oportunidades igualitárias, que promovam a inclusão como um direito de todos.

Essas mudanças paulatinamente não apenas efetivaram a entrada e permanência dos estudantes público-alvo da educação especial (EPAEE), ou seja, pessoas com deficiências físicas, sensoriais, transtornos globais do desenvolvimento e altas habilidades ou superdotação nas escolas, mas também adentraram as estruturas tecnológicas, filosóficas e metodológicas das unidades de ensino para o estabelecimento de ações de inclusão. Essas necessidades educacionais específicas para o desenvolvimento da aprendizagem aos EPAEE possuem como foco a equiparação de oportunidades. Entre elas, adequação curricular, tecnológica e de formação, o que suscitou uma grande demanda de formação inicial e continuada para atender esse público-alvo na escola regular.

Giroto, Poker e Omote (2012) apresentam diferentes necessidades vivenciadas pelos estudantes no cotidiano escolar. Evidenciam que a inclusão de fato não ocorre apenas com a matrícula do estudante e a garantia de frequentar a unidade escolar, mas sim com uma formação e capacitação adequada para os professores regulares e os professores do Atendimento Educacional Especializado (AEE). Não obstante, destacam a utilização de diferentes estratégias e metodologias diante da singularidade de cada estudante, a fim de que atinjam um desenvolvimento global.

Nessa perspectiva individualizada do estudante, diferentes documentos nacionais têm indicado modelos, ações e mudanças no sistema educacional. Autores como Bersch (2006), Cook e Polgar (2008), Galvão Filho (2012), Galvão Filho e Miranda (2011), Manzini e Santos (2002), Rocha e Deliberato (2012), Sankako e Braccialli (2014) e Schlünzen et al. (2011) apresentam a TA como um suporte para a efetivação da inclusão educacional e social, meio no qual inúmeros pesquisadores têm direcionado seus focos de estudos para resoluções de problemas pedagógicos.

O presente estudo toma como base três conceitos de TA que se complementam. Sartoretto e Bersch (2010, p. 21) contribuem com o conceito de TA como "[...] resolução de dificuldades funcionais de pessoas com deficiência" e que visa "[...] solucionar problemas de mobilidade, autocuidado, adequação postural, acesso ao conhecimento, produção de escrita, entre outros”. Judge, Floyd e Jeffs (2008) apontam que a TA é uma ferramenta para as atividades diárias e para o desenvolvimento das áreas sensoriais de comunicação e interação. Manzini e Santos (2002, p. 4) discorrem que a TA "[...] permite compensar as limitações do estudante permitindo a superação das barreiras decorrentes dos comprometimentos da deficiência".

Nesse sentido, a TA torna-se um instrumento imprescindível para a promoção da inclusão, autonomia e melhor qualidade de vida das pessoas com deficiência 
(Bersch, 2006; Manzini e Santos, 2002; Sartoreto e Bersch,2010). No Brasil, a TA tem por base a definição do Comitê de Ajudas Técnicas (CAT) da Coordenadoria Nacional para Integração da Pessoa Portadora de Deficiência (CORDE). ${ }^{1}$

Compete ao professor do AEE a função de adquirir os recursos necessários e corretos aos EPAEE, assim garante o artigo 59, inciso I, da Lei de Diretrizes e Bases da Educação Nacional (LDBEN) (Brasil, 1996), no qual é assegurada a oferta no AEE de "currículos, métodos, técnicas, recursos educativos e organização específicos para atender às suas necessidades".

Para melhor atender essa população, a Secretaria de Educação Continuada, Alfabetização, Diversidade e Inclusão (SECADI) e o Ministério da Educação e Cultura (MEC), em 2007, criaram um programa no qual disponibilizam às escolas públicas um conjunto de equipamentos de informática, mobiliários, materiais pedagógicos e de acessibilidade para a oferta do $\mathrm{AEE}$, em contrapartida os municípios devem ceder o espaço físico. O que se tangencia pelos professores e pesquisadores é o seguinte: Como o professor do AEE se utiliza dos recursos enviados pela SECADI/ MEC? De que forma ele os seleciona, no dia a dia, diante das especificidades dos estudantes? Esses recursos suprem a demanda vivenciada no AEE? Como os professores especialistas introduzem esses recursos no cotidiano dos estudantes?

Essas e outras tantas questões suscitam trabalhos colaborativos para adequação de procedimentos interdisciplinares desenvolvidos na SRM. Apesar de possuir características físicas, composta por materiais concretos, a SRM não se limita neles, mas possui um compromisso muito maior. Segundo Oliveira (2014, p. 3): "[...] a sala de recursos se caracteriza como um apoio complementar ou suplementar, isto é, não é substitutivo da ação pedagógica que ocorre na classe comum".

A SRM, como um ambiente favorecedor para o desenvolvimento dos estudantes, possui materiais e serviços apropriados para a obtenção dos estímulos, que por sua vez viabilizam interações e construções valiosas para o aprimoramento dos participantes. É o lócus no qual o professor do AEE mantém contato com o estudante, neste ele avalia suas potencialidades e habilidades, o que lhe dá propriedade para elaborar um PAI. Mediante a necessidade requerida pelo professor, recursos de alto e baixo ${ }^{2}$ custo podem estar envolvidos.

É necessária uma abordagem teórico-prática no processo de prescrição da TA, em razão das particularidades de cada pessoa com necessidades educacionais especiais (NEE). Nesse sentido, o tempo e o desenvolvimento de cada estudante devem ser respeitados pelo professor, pois a utilização da TA se diferencia confor-

1 Tecnologia assistiva é uma área do conhecimento, de característica interdisciplinar, que engloba produtos, recursos, metodologias, estratégias, práticas e serviços que objetivam promover a funcionalidade, relacionada à atividade e participação de pessoas com deficiência, incapacidades ou mobilidade reduzida, visando sua autonomia, independência, qualidade de vida e inclusão social (CAT, 2007).

2 Essa classificação ocorre em razão do custo final, complexidade e sofisticação. Um recurso de alto custo, por exemplo, utilizará materiais e procedimentos sofisticados, profissionais qualificados e produção em escala industrial. Em contrapartida, no de baixo custo, sua confecção é realizada de forma manual, artesanal, geralmente de forma individual (Galvão Fillho, 2012; Rocha, 2010; Sartoretto e Bersch, 2010). 
me a necessidade individual de cada pessoa, uma vez que o recurso ou a estratégia previamente selecionados podem ou não desenvolver a mesma funcionalidade para dois ou mais indivíduos (Sartoretto e Bersch, 2010; Schlünzen et al., 2011).

Em vista desse panorama, Queiroz (2015), ao analisar a concepção dos professores diante da funcionalidade dos recursos de TA disponíveis nas SRM, demonstra em sua pesquisa que os recursos de TA de alto e baixo custo ofertados pelo "Kit do MEC para Sala de Recursos"3 atendem parcialmente os estudantes com deficiência física. Não suprem a demanda da população atendida, pois estudantes com sérios comprometimentos necessitam de aquisições de outros recursos de TA.

Os dados que a autora compôs em um estudo acerca das concepções dos professores indicam que novos recursos de TA devem compor o "kit". Isso remete a uma reflexão para além da implementação de novos direcionamentos, apontando para novas políticas públicas para atender a SRM, a modificação da jornada de trabalho dos professores e a parceria com profissionais da saúde (Queiroz, 2015).

Diante de tais problematizações, outras podem ser visualizadas em diferentes trabalhos que ressaltam a construção e a adaptação de recursos pedagógicos no desenvolvimento do AEE (Alves, 2013; Cruz e Ioshimoto, 2010; Lourenço e Mendes, 2012; Miranda e Galvão Filho,2012; Queiroz,2015; Rocha e Deliberato,2012; Rodrigues, 2013; Sankako e Braccialli, 2014; Silva,2010). Destaca-se também o trabalho de Manzini (2013), que apresenta distintas variáveis para os estudos nas SRM, além de ressaltar que ainda são poucas e recentes as pesquisas que versam sobre a eficiência e eficácia do trabalho realizado no $\mathrm{AEE}$.

Diante da prerrogativa de que o professor do AEE identifica diferentes dificuldades na relação recurso versus sujeito atendido, associada à contingência das políticas públicas, e de que possui em sua formação e trajetória profissionais um conjunto de capacidades para desenvolver diferentes competências nos estudantes, bem como para estruturar o AEE, este estudo delimita-se a problematizar, perante isso, os procedimentos que o professor demanda ou recorre para a aquisição, adaptação e confecção de recursos de TA para atender às necessidades estabelecidas na sala do AEE? O que, por sua vez, garantirá aquisições para autonomia e independência em atividades da vida diária, escolares e sociais do estudante atendido.

Propõe-se a analisar as contingências pelas quais o professor do AEE está submetido ao realizar o desenvolvimento e aplicação dos recursos pedagógicos necessários aos estudantes da SRM.

Nesse contexto, surge a grande necessidade do professor do AEE de adquirir outros recursos de TA quando aqueles presentes na SRM não suprem as especificidades dos estudantes, bem como adaptar um recurso já existente quando possível, ou até mesmo confeccioná-lo quando de baixa complexidade.

\section{REFERENCIAL TEÓRICO}

A TA revela-se um instrumento de efetivação da inclusão escolar e a garantia de uma educação de qualidade, porém, em seu processo de desenvolvimento, ao ser

3 Programa Implantação de Salas de Recursos Multifuncionais (Brasil, 2007). 
realizado de forma inadequada, ocasiona o abandono do recurso, a suspensão do uso em razão da insatisfação com o resultado obtido, pois, sem o processo de sistematização, a TA não atinge o seu objetivo inicialmente proposto e, como consequência, não se obtém o progresso da aprendizagem (Rocha, 2010).

Assim, torna-se clara a necessidade de orientação e formação dos professores especialistas do AEE em relação ao processo de desenvolvimento e manuseio desses recursos, uma vez que garantem a equiparação de oportunidades educacionais, acessíveis a todos, a partir de sua utilização (Miranda e Galvão Filho, 2012; Rodrigues e Capellini, 2011; Verussa, 2009).

Queiroz (2015), ao analisar a concepção dos professores diante da funcionalidade dos recursos de TA disponíveis na SRM, selecionou como público-alvo professores do AEE de deficiência física e, para a coleta de dados, utilizou o School Function Assessment e entrevista semiestruturada. A autora aponta que, ainda que as SRM possuam recursos de TA de alto e baixo custo ofertados pelo "Kit do MEC para sala de recursos", surge na SRM necessidades de aquisição e/ou adaptação de outros materiais, pois a oferta do kit não supre a demanda advinda das particularidades dos estudantes.

Ao olhar para a TA diante das diferentes e específicas necessidades na SRM, identifica-se a necessidade da realização de um processo sistematizado para seu desenvolvimento e estabelecimento, a fim de se obter um recurso que efetivamente alcance seu objetivo e supere as barreiras identificadas ao processo de aprendizagem.

Manzini e Santos (2002, p. 5-6) elaboraram um fluxograma que se destina à “[...] orientação para os profissionais da educação, no sentido de encontrarem soluções de objetos que auxiliem o aprendizado de pessoas com necessidades especiais". O fluxograma apresenta processo sistematizado para o desenvolvimento de ajudas técnicas, que contempla sete etapas:

1. entender a situação que envolve o estudante;

2. gerar ideias;

3. escolher a alternativa viável;

4. representar a ideia;

5. construir o objeto para experimentação;

6. avaliar o uso do objeto;

7. acompanhar o uso.

Os autores ressaltaram a necessidade de o fluxograma ser realizado de forma individual, pois "cada necessidade é única e, portanto, cada caso deve ser estudado com muita atenção"(Manzini e Santos, 2002,p. 6). Também deixam clara a exigência de que a experimentação e a reavaliação, por meio do fluxograma, desde a etapa 1 , deve ser constante, com a finalidade de verificar se a TA contempla o objetivo proposto. Ou seja, analisar se as necessidades identificadas inicialmente foram supridas, utilizando o fluxograma no intuito de continuidade, não permitindo que o processo seja encerrado até que o estudante supere totalmente seus obstáculos. Bersch (2006, p. 283), a fim de fornecer orientação aos professores quanto à implementação e acompanhamento da TA com base na California State University Northridge - Center on Disabilities, propõe uma sequência de dez passos: 
1. histórico e conhecimento do aluno/usuário da TA;

2. identificação das necessidades no contexto escolar;

3. identificação de objetivos a serem alcançados pela equipe;

4. avaliação das habilidades do aluno;

5. seleção/confecção e teste de recursos;

6. tempo para aprender a utilizar o recurso;

7. orientação para aquisição;

8. implementação da TA;

9. seguimento e acompanhamento do aluno na utilização da TA;

10. desenvolvimento e fortalecimento de equipe durante todo o processo.

De acordo com Gonçalves (2010, p. 45), a preocupação tanto de Manzini e Santos (2002) como de Bersch (2006) quanto ao auxílio aos profissionais da educação no desenvolvimento da TA resulta no desenvolvimento de sequências semelhantes e possui enfoque maior no "[...] diagnóstico da situação, verificação das necessidades do aluno, construção do recurso, avaliação do seu uso e acompanhamento do aluno durante o uso do recurso adaptado".

Alves (2013), em sua pesquisa, relata a existência de grande quantidade de trabalhos da área de TA e traça um panorama da literatura nacional e internacional, constatando que a literatura internacional tem seu foco principalmente nos fatores e variáveis que influenciam o uso bem-sucedido, o abandono, a indicação e implementação dos recursos de TA, entre outros, enquanto nas pesquisas nacionais o que predomina são estudos que indicam os melhores recursos que favoreçam o desenvolvimento do estudante.

Após um sistemático levantamento bibliográfico, Alves (2013) identificou e disponibilizou diferentes formas de implementação de recursos de TA para utilização no Brasil; identificou, ainda, dois modelos de avaliação mais regularmente utilizados: o Matching Person and Technology (MPT); e o Assistive Technology Device Predisposition Assessment (ATD-PA). Apresenta como resultado os dois modelos de avaliação como bons norteadores para o processo de indicação e implementação dos recursos de TA, bem como disponibiliza o manual e avaliação $A T D-P A B r-$ contextualizado com a realidade brasileira (Alves, 2013). Cabe destacar que a autora indica a continuidade das pesquisas na utilização do modelo de avaliação adaptado.

Gonçalves (2010), em seu estudo com crianças com paralisia cerebral, utilizou como base teórica o fluxograma de Manzini e Santos (2002) e os dez passos de Bersch (2006). Nesse estudo, a autora constatou a necessidade de planejamento para a adaptação da TA, de forma participativa com o estudante, com adaptações que devem ser realizadas de modo consciente e utilizável.

Rocha (2010), em sua tese sobre o processo de prescrição e confecção de recursos para crianças com paralisia cerebral, concluiu que para a prescrição dos recursos foram necessárias etapas com procedimentos específicos, sendo essencial a sistematização do processo de desenvolvimento da TA. Nesse sentido, revelaram-se como desafio as formas de raciocínio para tal sistematização, sobretudo a partir das seguintes questões: Em que e no que o professor se baseia para transpor esse processo?

Em continuidade aos estudos que relacionam avaliação e prescrição da TA, temos o de Lourenço e Mendes (2012). Ao realizarem uma proposta preliminar 
de sistematização para a implementação de recursos de alta TA com estudantes com paralisia cerebral, utilizaram como referencial teórico o "modo Homem-Atividade-Tecnologia Assistiva (HAAT)", de Cook e Polgar (2008). Como conclusão, Lourenço e Mendes (2012) observaram a complexidade que envolve o processo de implantação da TA, por abranger múltiplas variáveis, e que, apesar de essa ser uma área promissora, ainda demanda muito investimento e qualificação profissional.

Verussa (2009), valendo-se da aplicação de um questionário intitulado “Tecnologia Assistiva para Educação (TAE)”, buscou identificar se os professores sabiam manusear recursos de TA com os estudantes com deficiência física, visual e auditiva. Constata a disparidade entre o ideal e a realidade vivenciada na pesquisa, uma vez que os recursos que chegavam às escolas muitas vezes não eram introduzidos no cotidiano escolar em razão dos professores não possuírem o conhecimento para o manuseio correto desses recursos disponibilizados na SRM.

Urban e Mendes (2012) realizaram uma pesquisa sobre os recursos de TA utilizados por cinquenta estudantes com paralisia cerebral, por meio de um roteiro de entrevista semiestruturada com os pais/responsáveis. Identificaram que, entre o total de estudantes, trinta e cinco utilizavam recursos de TA. Também destacaram o fato como relevante para o processo de escolarização, promoção da funcionalidade e autonomia dos estudantes. Por fim, as autoras concluíram que apenas dezesseis alunos utilizavam os recursos de TA na escola, constatando a necessidade de sua implementação no processo escolar para todos os estudantes.

Deliberato (2005), em sua pesquisa com recursos alternativos ou suplementares à fala, realiza a seleção, adequação e implementação de diferentes recursos comunicativos com a finalidade de favorecer e ampliar a comunicação dos estudantes. $\mathrm{O}$ estudo foi desenvolvido com treze estudantes de classes especiais e um estudante do ensino regular incluído, e a autora destaca a necessidade de processos de avaliação e seleção da TA.

\section{PROCEDIMENTOS METODOLOGICOS}

\section{CARACTERIZAÇÃO DA PESQUISA}

A presente pesquisa possui como base a abordagem qualitativa, ao considerar que o objeto em estudo busca a concepção dos professores diante do processo de desenvolvimento e aplicação de recursos de TA. Atendeu aos requisitos éticos ${ }^{4}$ propostos pelo Comitê de Ética.

\section{PARTICIPANTES E LOCAL DA PESQUISA}

A fim de realizar o processo de seleção dos participantes, optou-se por critérios determinados por meio das seguintes etapas:

4 A pesquisa foi encaminhada e aprovada pelo Comitê de Ética em Pesquisa (CAAE), da Faculdade de Ciências e Tecnologia (FCT), UNESP, campus Presidente Prudente, sob n. 35885214.0.0000.5402. 
- mapeamento realizado com coordenadores a respeito de professores experientes atuantes no AEE nas cidades de Presidente Prudente, Marília, Bauru, Araraquara e Araçatuba;

- seleção dos professores pelas experiências profissionais no AEE, bem como da prática no processo de aquisição, confecção e adaptação de recursos pedagógicos;

- apresentação do projeto para os professores selecionados e o aceite em participar;

- autorização por meio do preenchimento do Termo de Consentimento Livre e Esclarecido (TCLE) pelos professores do AEE.

A caracterização da população foi determinada conforme a atuação profissional dos sujeitos: professores atuantes no AEE no ensino infantil e/ou fundamental ciclo I ( $1^{\circ}$ ano ao $5^{\circ}$ ano), da rede municipal de ensino, que, além de utilizarem os recursos pedagógicos de TA disponibilizados pela SECADI/MEC, adaptam materiais e/ou adquirem ou confeccionam outros recursos pedagógicos para o AEE.

\section{PROCEDIMENTOS PARA COLETA DE DADOS}

\section{Roteiro de entrevista}

Foi utilizado como técnica de coleta de dados um roteiro de entrevista. Para Marconi e Lakatos (2010, p. 198), "a entrevista tem como objetivo principal a obtenção de informações do entrevistado, sobre determinado assunto ou problema”.

Entre as várias técnicas de entrevista, adotou-se a entrevista semiestruturada, por ser mais apropriada e favorecer o desenvolvimento da pesquisa com elaboração de perguntas, direcionamentos aos temas, além de permitir reajustes no decorrer de sua execução a partir das necessidades que possam surgir, como o desvio de assunto do entrevistado (Manzini, 2003, 2004; Marconi e Lakatos, 2010).

O planejamento e a confecção do roteiro de entrevista foram realizados conforme o proposto por Manzini (2003): consiste em um roteiro semiestruturado, elaborado pelos pesquisadores e submetido à validação e adequação com a apreciação de dois juízes e, posteriormente, com a entrevista-piloto, tendo por finalidade obter informações acerca do processo de desenvolvimento e aplicação de recursos pedagógicos utilizados no AEE. Para tornar o roteiro de entrevista exequível ao tema, ele foi constituído por três blocos de perguntas, descritos a seguir:

- Bloco 1: informações pessoais e profissionais sobre o professor: constituído por quatro questões abertas, possuindo a finalidade de obter informações acerca da formação inicial, continuada e experiência profissional:

1. nome, data de nascimento e gênero;

2. experiência docente e no AEE;

3. formação inicial e continuada, quanto à instituição, curso e ano de conclusão;

4. formação em educação especial, quanto à instituição, área e anos de conclusão.

- Bloco 2: informações sobre experiências na SRM e práticas pedagógicas quanto ao processo de aquisição, confecção e adaptação de recursos peda- 
gógicos: composto de duas questões abertas, tendo como finalidade obter informações sobre a concepção do professor e sua prática no AEE:

1. Fale um pouco da sua experiência com os alunos que atende e dos recursos pedagógicos para os alunos da SRM;

2. Você costuma confeccionar, adquirir e/ ou adaptar recursos pedagógicos para os alunos na SRM?

- Bloco 3: informações diretas sobre o processo de aquisição, confecção e adaptação de recursos pedagógicos: composto de dez questões semiabertas, tendo como finalidade obter informações sobre quais os passos utilizados pelo professor para realizar a aquisição, confecção e adaptação de recursos pedagógicos na oferta do AEE, tomando como base o fluxograma proposto por Manzini e Santos (2002):

1. Como você identifica que um aluno necessita de um recurso pedagógico mais apropriado?;

2. Como você escolhe o melhor recurso pedagógico?;

3. Você costuma ouvir a opinião do seu aluno e de seus familiares durante a escolha do recurso pedagógico?;

4. Você faz o levantamento dos recursos pedagógico mais viáveis? Como?;

5. A partir desse levantamento, como você realiza a seleção do recurso pedagógico mais viável para cada aluno?;

6. Você se preocupa com o tipo de material e dimensões do recurso pedagógico? Como você os define/escolhe?;

7. Você realiza a experimentação dos recursos pedagógicos? Como e em quais situações?;

8. De que forma você in troduz o recurso pedagógico no cotidiano do aluno?;

9. Você avalia o uso do recurso pedagógico? Como?;

10. Você faz o acompanhamento do uso do recurso pedagógico? Como?

\section{Coleta de dados}

A coleta de dados das entrevistas foi iniciada pelos pesquisadores após a confecção e validação do roteiro de entrevista e da aprovação da pesquisa pelo Comitê de Ética e Pesquisa. Houve a aceitação dos participantes, e as entrevistas ocorreram em diferentes locais e horários, que em cada caso foram determinados conforme a preferência e disponibilidade dos participantes.

\section{Análise de conteúdo}

A organização dos dados derivados das entrevistas foi realizada por meio da análise de conteúdo, utilizando a técnica proposta por Bardin (2011), que antevê a concretização da interpretação dos dados com a organização da análise, a codificação, a categorização e a inferência.

A transcrição das entrevistas apresentou-se como forma de transpor as informações do relato dos entrevistados, o que permitiu a eles emitir suas primeiras impressões diante do material (Manzini, 2012). Entre as normas de transcrição, adotou-se na pesquisa a proposta pelo Projeto da Norma Urbana Oral Culta do 
Rio de Janeiro (NURC) (Preti e Urbano, 1990), ao proporcionar registro do relato verbal, bem como o contexto da entrevista e suas reações, que proporcionam um panorama para inferências do pesquisador no processo de análise (Bardin, 2011).

Diante desse propósito, todas as entrevistas foram transcritas na íntegra, organizadas em arquivos digitais em pastas individuais e identificadas. Inicialmente as transcrições foram impressas, e marcações foram realizadas para selecionar diferentes informações. Posteriormente foi realizada a leitura flutuante, na qual foram destacados os trechos mais pertinentes aos objetivos da pesquisa. Por fim, realizamos a análise de conteúdo, por meio da análise categorial temática, utilizando como base o fluxograma de Manzini e Santos (2002).

\section{RESULTADOS E DISCUSSÃO}

Os resultados serão apresentados e discutidos mediante as sete etapas, aqui denominadas de temas, propostas pelo fluxograma de Manzini e Santos (2002), elegidas como itens da entrevista semiestruturada. Posteriormente à análise de conteúdo, surgiram subcategorias derivadas de cada categoria, o que ocorreu em cada um dos sete temas. Para cada tema foram apresentadas sínteses que suscitam a problemática do estudo, de modo que pudesse responder como os professores, representantes das escolas concentradas em pontos de grande relevância do estado de São Paulo, contingenciam seus fluxos de recursos para atender de forma exequível à demanda surgida na SRM.

\section{TEMA 1 - ENTENDER A SITUAÇÃO QUE ENVOLVE O ESTUDANTE}

Foram estabelecidos como categorias desse tema quatro elementos descritivos propostos no fluxograma:

1. escutar os desejos dos estudantes;

2. identificar características físicas/psicomotoras;

3. observar a dinâmica do estudante no ambiente escolar; e

4. reconhecer o contexto social que envolve o estudante (Quadro 1).

A categoria 1 revela que, apesar de os estudantes manifestarem interesse por determinados recursos, sua utilização decorre não de seu desejo, mas da necessidade identificada pelo professor; de qualquer maneira, o estudante é questionado e manifesta sua opinião no processo de utilização.

A categoria 2 revela como a avaliação realizada na SRM ou com o Plano de Ensino Individualizado (PEI) atua como um favorecedor para o processo de compreender a situação que envolve o estudante. Os professores pautam-se na avaliação, mas não se restringem a ela, uma vez que apresentam constantes adequações e novas modificações na rotina do estudante.

A categoria 3 revela uma preocupação em observar os estudantes, principalmente no tocante às suas capacidades e habilidades, com um viés em seu desenvolvimento na sala comum e na interação com os objetos já pertencentes à SRM, composta de diferentes materiais disponibilizados pelo Programa Implantação de Salas de Recursos Multifuncionais (Brasil, 2007). 
A categoria 4 revela uma das possibilidades pela qual o professor pode valer-se para a construção da situação que envolve o participante e destacar diferentes perspectivas do estudante, como o contato com pessoas de fácil acesso e que permeiam o universo do estudante, o que contribui para maior delimitação de seu trabalho.

Em conclusão, diante das falas dos participantes, fica evidente a preocupação com a avaliação dos estudantes, a exploração e interação com o objeto, e o contato com a família e com o professor da sala comum.

No tocante à avaliação, destaca-se uma preocupação dos professores em compreender os aspectos pessoais e coletivos na sala comum, no entanto não é apresentada como um instrumento mensurador, mas de seleção e adequação do recurso pedagógico. Para Oliveira (2014), a avaliação do professor especializado é essencial para um bom desenvolvimento do EPAEE, pois perpassa não apenas a identificação de suas habilidades, capacidades e necessidades, mas busca encontrar caminhos para um melhor acesso aos conteúdos específicos do currículo trabalhados no ensino comum. Propicia também a identificação e a seleção dos recursos mais adequados para os estudantes diante de suas singularidades.

O papel da família em relação à escolarização de seus filhos mudou nos últimos anos. Sua entrada na escola hoje, apesar de tímida, é ativa e contribui para um bom desenvolvimento dos estudantes. É inegável que ainda enfrentamos dilemas no que diz respeito à relação entre família e escola, no entanto estes são superáveis para um bom desenvolvimento do estudante (Melchiori, Rodrigues e Maia, 2014).

Não obstante o objetivo de compreender o estudante, exposto nas categorias do tema 1, “[...] a literatura descreveu que a primeira etapa para a implementação da TA na escola deve permitir entender a situação que envolve o estudante a fim de ampliar a sua participação no processo de ensino e aprendizagem" (Rocha e Deliberato, 2012, p. 1), o que corrobora com as proposições deste trabalho.

Quadro 1 - Entender a situação que envolve o estudante

\begin{tabular}{|c|c|c|}
\hline Categorias & Subcategorias & Extrato de falas \\
\hline 1 & Conversar com o estudante & $\begin{array}{l}\ldots] \text { assim, eu percebo que a opinião deles é } \\
\text { muito importante para mim }[\ldots](\mathrm{P} 3)\end{array}$ \\
\hline 2 & $\begin{array}{l}\text { Avaliação e plano } \\
\text { de desenvolvimento } \\
\text { individualizado }\end{array}$ & $\begin{array}{l}\text { [...] preciso de uma avaliação, não só antes } \\
\text { de iniciar o atendimento, mas tem que } \\
\text { acontecer de forma constante, não só dentro } \\
\text { da sala de recurso, eu tenho que observar esse } \\
\text { aluno também em sala de aula [...] (P4) }\end{array}$ \\
\hline 3 & $\begin{array}{l}\text { Exploração e interação } \\
\text { com o objeto, o contato } \\
\text { com a família e com } \\
\text { o professor comum }\end{array}$ & $\begin{array}{l}{[\ldots] \text { eu preciso saber a necessidade dele dentro da sala }} \\
\text { de aula, eu preciso de contato com o professor da sala } \\
\text { regular e, em alguns momentos, com a família [...] (P4) }\end{array}$ \\
\hline 4 & $\begin{array}{l}\text { Ouvir opinião } \\
\text { dos funcionários, } \\
\text { professores e gestores }\end{array}$ & $\begin{array}{c}{[\ldots] \text { busco todas as informações do aluno com a }} \\
\text { família }[\ldots . .] \text { depois eu busco ver o aluno dentro da } \\
\text { escola, [...] ouvir a opinião dos funcionários [...] (P5) }\end{array}$ \\
\hline
\end{tabular}

Fonte: banco de dados da pesquisa.

Elaboração dos autores. 
TEMA 2 - GERAR IDEIAS

Foram estabelecidos como categorias desse tema quatro elementos descritivos propostos no fluxograma:

1. conversar com os usuários;

2. buscar soluções existentes;

3. pesquisar materiais que podem ser utilizados; e

4. pesquisar alternativas para confecção do objeto (Quadro 2).

\section{Quadro 2-Gerar ideias}

\begin{tabular}{|c|c|c|}
\hline Categorias & Subcategorias & Extrato de falas \\
\hline \multirow{3}{*}{1} & $\begin{array}{c}\text { Conversa com } \\
\text { profissionais da escola }\end{array}$ & $\begin{array}{l}{[. .] \text { com a família, depois eu vejo o aluno dentro da }} \\
\text { escola [...] ouvir a opinião dos funcionários (P5) }\end{array}$ \\
\hline & Conversa com a família & $\begin{array}{l}{[\ldots] \text { fazemos a primeira entrevista de matrícula, aí, }} \\
\text { após o primeiro mês de aula [...], fazemos um retorno } \\
\text { com as famílias e nós conversamos. [...] (P1) }\end{array}$ \\
\hline & $\begin{array}{l}\text { Ouvir a opinião } \\
\text { do estudante }\end{array}$ & $\begin{array}{l}{[\ldots . .] \text { nós perguntamos sim, então, muitas vezes }} \\
\text { eles entram e querem ir primeiro pro computador, } \\
\text { aí nós combinamos rotinas e regras [...] (P1) }\end{array}$ \\
\hline \multirow{4}{*}{2} & $\begin{array}{l}\text { Exploração e/ou } \\
\text { experimentação de } \\
\text { diferentes materiais } \\
\text { disponíveis na SRM }\end{array}$ & $\begin{array}{c}\ldots] \text { nós vamos fazendo testes mesmo, eu mostro } \\
\text { e vejo o que ele vai conseguir, eu já sei que no } \\
\text { computador ele consegue com o acionador }[\ldots] \\
\text { para ele é melhor se tiver as partes coloridas } \\
\text { porque ele vai pelas cores }[. . .](\mathrm{P} 1)\end{array}$ \\
\hline & Experiência profissional & $\begin{array}{l}\text { [...] quando eu cheguei aqui no AEE, fazia muita } \\
\text { coisa de isopor, hoje tudo eu faço é de madeira, } \\
\text { então não sei, eu evolui um pouquinho [...] (P3) }\end{array}$ \\
\hline & Trabalho colaborativo & $\begin{array}{l}\text { [...] eu falo que o professor de sala do AEE, ele } \\
\text { tem que ser parceiro do regular [...], a gente até } \\
\text { usa o termo trabalho colaborativo, tem que ser } \\
\text { constante, eu falo semanal, mas às vezes essa } \\
\text { conversa, esse diálogo tem que ser diário [...] (P4) }\end{array}$ \\
\hline & Funcionalidade do recurso & $\begin{array}{l}\text { [...] a gente aplica em sala de recurso e sala de aula } \\
\text { regular, é aí que a gente vai ver se teve funcionalidade; } \\
\text { caso não, a gente volta e vamos adequá-lo [...] (P4) }\end{array}$ \\
\hline 3 & $\begin{array}{l}\text { Repertório de materiais } \\
\text { disponíveis na SRM e } \\
\text { pesquisas e estudos }\end{array}$ & $\begin{array}{c}\text { [...] mas é em cima do que eu já tenho, porque } \\
\text { quando eu não tinha era acerto e erro, tentar } \\
\text { mesmo, começar por um lado; se não deu, } \\
\text { fico pensando na estratégia. [...] (P3) }\end{array}$ \\
\hline 4 & $\begin{array}{l}\text { Avaliação situacional } \\
\text { e apoio tecnológico }\end{array}$ & $\begin{array}{l}\text { [...] para conhecer meu aluno, tenho que atuar } \\
\text { com ele, observar em todos os espaços da escola, } \\
\text { analisar também quais são as habilidades, não só } \\
\text { observar a dificuldade [...] é por meio delas que eu } \\
\text { consigo elaborar a tecnologia assistiva. [...] (P4) }\end{array}$ \\
\hline
\end{tabular}

Fonte: banco de dados da pesquisa.

Elaboração dos autores. 
A categoria 1 revela que o contato com familiares, profissionais da educação e equipe multidisciplinar respalda o professor para a compreensão e possibilidade de novas alternativas aos estudantes, uma vez que são áreas que extrapolam suas competências. A comunicação com a família no momento de gerar ideias é assertiva, pois, ainda que não conheça as capacidades e habilidades do estudante, no âmbito educacional a família possui propriedade para informar sobre os desejos e preferências do aluno, favorecendo a identificação de ideias para o recurso pedagógico.

Os professores ouvem a opinião e os desejos dos estudantes como essenciais, porém cada um os realiza em momentos e formas diferentes. Mas destaca-se em comum a utilização do recurso sem imposição, a fim de que se torne algo prazeroso e confortável ao estudante.

A categoria 2 revela que os professores utilizaram com os estudantes diferentes recursos disponíveis nas SRM; partindo da exploração dos objetos, o professor verifica quais as possibilidades necessárias para a utilização funcional de um recurso. Acaba que essa experimentação resulta em uma forma de observar/avaliar as capacidades e habilidades dos estudantes.

A experiência profissional é elemento decisivo no uso do recurso pedagógico, pois o repertório dessa experiência possibilita articular fatos atuais com experiências similares já realizadas. Revela também a presença do trabalho colaborativo no cotidiano dos participantes, tornando-se parte do processo de utilização do recurso pedagógico, pois há na consultoria de profissionais especialistas conhecimentos e práticas distintas que favorecem o desenvolvimento dos estudantes no AEE e na sala regular.

Da mesma forma, os professores pautam suas escolhas com base na funcionalidade dos recursos para atender às características do estudante, assim como no aspecto ambiental, pois a utilização de um recurso com grandes dimensões na sala de aula comum torna-se inviável.

A categoria 3 revela que dispor de uma diversidade de recursos de TA na SRM corrobora para que o professor tenha opções para adaptar novas situações de forma apropriada e assertiva, minimizando as chamadas tentativas e erro.

A categoria 4 revela a avaliação situacional, permeada pela observação diária do estudante em suas capacidades e habilidades, bem como a utilização da tecnologia como uma das alternativas. Em síntese, na análise dos relatos observam-se diferentes contingências profissionais ao identificar e levantar meios para a construção, aquisição ou adaptação de recursos pedagógicos. Destaca-se uma predominância de ações nas categorias conversar com usuários e buscar soluções existentes.

Identificou-se nos dois primeiros temas uma participação ativa da família na compreensão do universo do estudante e das possibilidades de ideias para os recursos pedagógicos. A participação da família e do professor da sala comum apresenta-se como condição essencial para a construção de uma efetiva compreensão do universo do estudante, pois, conforme Melchiori, Rodrigues e Maia (2014, p. 10), “[...] todas as ações e decisões escolares devem ser compartilhadas com a família. O contato com eles já pode ocorrer de forma amistosa por ocasião da matrícula, dialogando com pai, mãe ou outros responsáveis, juntos e/ou separados [...]".

Emerge dos resultados o processo de exploração ou experimentação dos recursos pelos EPAEE, a fim de mensurar as habilidades e capacidades desses 
estudantes. Destaca-se que a SRM é equipada com recursos e mobiliários disponibilizados pelo Programa Implantação de Salas de Recursos Multifuncionais (Brasil, 2007), no entanto, para a utilização desses recursos, os professores realizam adaptações, confecções ou mesmo a compra de recursos que melhor auxiliam os estudantes. Nessa propositura, Queiroz (2015) conclui que os recursos oferecidos pelo programa não suprem a demanda vivenciada pelo EPAEE na SRM, necessitando de novas aquisições, construções e adaptações.

\section{TEMA 3 - ESCOLHER A ALTERNATIVA VIÁVEL}

Foram estabelecidos como categorias desse tema dois elementos descritivos propostos no fluxograma:

1. considerar as necessidades a serem atendidas e

2. considerar a disponibilidade de recursos materiais para a construção do objeto (Quadro 3).

\section{Quadro 3 - Escolher a alternativa viável}

\begin{tabular}{|c|c|c|}
\hline Categorias & Subcategorias & Extrato de falas \\
\hline \multirow{6}{*}{1} & Avaliação & $\begin{array}{l}\text { Durante os primeiros atendimentos, nós fazemos } \\
\text { como uma avaliação diagnóstica [...] (P1) }\end{array}$ \\
\hline & $\begin{array}{l}\text { Relatório informativo } \\
\text { anual }\end{array}$ & $\begin{array}{c}{[\ldots] \text { no final do ano, para todas as crianças, }} \\
\text { nós fazemos um relatório informativo do } \\
\text { ano, consta todos os bimestres }[\ldots](\mathrm{P} 1)\end{array}$ \\
\hline & Pesquisa de base acadêmica & $\begin{array}{l}{[\ldots . .] \text { então o método mais rápido que a gente tem hoje }} \\
\text { na nossa mão, uma ferramenta que ajuda muito é a } \\
\text { internet, livros, diferentes cursos, seminários [...] (P5) }\end{array}$ \\
\hline & Experiência profissional & $\begin{array}{l}\text { [...] a gente tem que pensar dependendo um pouco } \\
\text { de cada deficiência, para cada deficiência, para } \\
\text { cada necessidade e cada criança, pois cada um tem } \\
\text { uma habilidade, uma circunstância }[\ldots](\mathrm{P} 4)\end{array}$ \\
\hline & Faixa etária dos estudantes & $\begin{array}{c}\text { [...] sim, pensando na faixa etária que eu estou } \\
\text { trabalhando. Se é um jogo para educação } \\
\text { infantil? O que é? Como eu faria? Uma } \\
\text { coisa chamativa, algo grande? [...] }\end{array}$ \\
\hline & $\begin{array}{l}\text { Olhar as capacidades, } \\
\text { habilidades e limitações }\end{array}$ & $\begin{array}{l}\text { [...] temos a dificuldade, habilidade e potencialidade, } \\
\text { isso dentro de todo o bimestre }[\ldots](\mathrm{P} 1)\end{array}$ \\
\hline \multirow[b]{2}{*}{2} & $\begin{array}{l}\text { Explorar os recursos } \\
\text { da SRM }\end{array}$ & $\begin{array}{c}{[\ldots] \text { conhecer a sua sala de aula, então apresento, }} \\
\text { verifico a forma como ele segura, o que ele } \\
\text { conhece, o que ele não conhece }[. . .](\mathrm{P} 1)\end{array}$ \\
\hline & Aquisição de materiais & $\begin{array}{l}{[\ldots] \text { recursos que eu compro, são mais jogos; isso }} \\
\text { é importante para qualquer criança, [...] comprar } \\
\text { um jogo e fazer uma adequação; agora, se eu } \\
\text { penso no ensino fundamental, é leitura e escrita } \\
\text { mesmo, hoje eu tenho que criar [...] (P3) }\end{array}$ \\
\hline
\end{tabular}

Fonte: banco de dados da pesquisa.

Elaboração dos autores. 
A categoria 1 revela que, apesar de os professores circunstancialmente conhecerem quais os recursos adequados e seus materiais, a interação do estudante é decisiva na escolha. Nesse momento, ainda que já tenha ocorrido uma avaliação prévia, ela retorna, no intuito de conhecer uma nova realidade vivenciada pelo estudante. A continuidade das ações dos anos subsequentes denota que eles não estão completamente às cegas, o trabalho sistematizado descrito por meio dos relatórios informativos anuais, ainda que incompletos, direcionam o olhar do professor para a escolha das alternativas mais viáveis direcionadas aos estudantes a partir do que eles já realizam.

A mesma categoria revela também duas grandes vertentes de pesquisas: livros e cursos e a internet. Destaca-se essa subcategoria pela facilidade de acesso ao conhecimento por meio da pesquisa de diferentes modelos e lugares no mundo, disponíveis em meio às TIC.

Os entrevistados apresentam a mesma maneira de observar com base na experiência profissional, construída por meio da práxis pedagógica com os EPAEE. Ou seja, ainda que as subcategorias preestabelecidas possuam em sua concepção diferentes caminhos, elas apresentam a mesma ação, isto é, a experiência profissional.

A categoria 2 revela novamente a incidência da necessidade de se manter a SRM bem equipada, com diferentes recursos e mobiliários, pois é nela que se dá início a todo atendimento individualizado para as necessidades dos estudantes. Com base na fala dos participantes, evidencia-se em suas ações um processo natural para o desenvolvimento das capacidades e habilidades no AEE. A aquisição de diferentes materiais comuns a todas as crianças e sua posterior adaptação possibilitam ao estudante uma imersão no contexto escolar comum sem maiores diferenças, ao tornar o recurso invisível aos olhos dos outros estudantes, ou seja, interferir o mínimo possível em um recurso pedagógico ao adaptá-lo de modo que aproxime o EPAEE da realidade da sala de aula comum.

Em síntese, no que se refere à compreensão dos professores mediante suas falas a respeito das oportunidades da escolha de alternativas viáveis para a aquisição, confecção e adaptação dos recursos pedagógicos, é possível notar que se sobressai novamente a avaliação, que ocorre de forma constante, com a observação das especificidades dos estudantes. Rocha e Deliberato (2012) confirmam essa situação ao identificarem as necessidades de serviço, recursos e estratégias de TA para estudantes com paralisia cerebral. Os autores realizaram o estudo de forma sistemática para o processo de escolha das alternativas mais viáveis aos estudantes selecionados.

Quanto às formas de pesquisa, percebe-se um dado substancial para a utilização das TIC, principalmente quando são notórias a ampliação e a divulgação de diferentes informações. Nessa perspectiva, cabe ressaltar como exemplos o Catálogo Nacional de Produtos de Tecnologia Assistiva, o Portal Nacional de Tecnologia Assistiva, além de uma grande variedade em sítios internacionais, vídeos de adaptação e confecção de recurso de baixo custo disponíveis on-line (ITS Brasil).

\section{TEMA 4 - REPRESENTAR A IDEIA}

Foram estabelecidos como categorias desse tema três elementos descritivos propostos no fluxograma:

1. definir materiais; 
2. definir as dimensões do objeto; e

3. elaborar desenhos, modelos e ilustrações.

Nas entrevistas, representar a ideia de recursos pedagógicos, seja para construir, adaptar ou adquirir, não constou nas falas a categoria 3 (Quadro 4).

A categoria 1 revela diferentes formas de se pensar e utilizar os materiais para os recursos pedagógicos, no entanto apresentam no exposto uma particularidade em comum: a exploração de materiais para verificar se são confortáveis, seguros e oferecem maior autonomia para os estudantes.

Os entrevistados demonstram cuidado em elaborar um material de qualidade que garanta sua utilização por um longo período, como encapar o material com plástico adesivo, com espuma vinílica acetinada (EVA), utilizar materiais mais duradouros, tais como madeira, entre outros. Adicionalmente, destaca-se a utilização de recursos e materiais seguros, que não sejam escorregadios, ásperos, pontiagudos, entre outras características que afetariam diretamente a segurança ou a saúde dos estudantes. A razão desses cuidados se deve a sua utilização constante, que ocorre em três ambientes: SRM, sala comum e na casa do estudante.

A categoria 2 revela que o foco é o estudante, não o recurso. $\mathrm{O}$ objetivo final é a funcionalidade do recurso para o processo de superação de barreiras impostas em decorrência da deficiência. Da mesma forma, revela como necessidade a avaliação do contexto pessoal e social de cada estudante perante os recursos pedagógicos.

Apesar de os professores realizarem um processo de avaliação e estudo do recurso adequado ao estudante, diante de cada tarefa, a opinião deles é essencial,

Quadro 4-Representar a ideia

\begin{tabular}{|c|c|c|}
\hline Categorias & Subcategorias & Extrato de falas \\
\hline \multirow{3}{*}{1} & Adequação & $\begin{array}{l}{[\ldots] \text { exemplo no computador, o tamanho da fonte, eu }} \\
\text { vou colocando e perguntando: é adequado, é melhor pra } \\
\text { você, que cor você quer, mais escuro, mais claro? (P1) }\end{array}$ \\
\hline & Qualidade do material & $\begin{array}{l}{[\ldots] \text { materiais de qualidade possuem uma vida longa, }} \\
\text { para atingir os objetivos e ser algo duradouro }[. . .](\mathrm{P} 2)\end{array}$ \\
\hline & Segurança & $\begin{array}{c}{[\ldots] \text { nada com ponta, nada muito }} \\
\text { áspero, que machuque }[\ldots](\mathrm{P} 1)\end{array}$ \\
\hline \multirow{4}{*}{2} & $\begin{array}{l}\text { Características } \\
\text { do estudante }\end{array}$ & $\begin{array}{l}\text { [...] tamanho é a primeira coisa, o tamanho depende da } \\
\text { idade da criança e sua coordenação motora [...] (P1) }\end{array}$ \\
\hline & Avaliação & $\begin{array}{l}{[\ldots . .] \text { vai um pouquinho do que o médico diz, um laudo }} \\
\text { ou relatório médico me traz dados importantes, não } \\
\text { adianta pensar em um recurso de ampliar fontes se } \\
\text { essa criança tem só uma visão central [...] (P4) }\end{array}$ \\
\hline & $\begin{array}{l}\text { Questionar o aluno sobre } \\
\text { o que achou do recurso }\end{array}$ & $\begin{array}{l}{[\ldots] \text { eu crio o recurso e dou na mãozinha dele, }} \\
\text { aí eu vou falando: tá difícil? [...] (P3) }\end{array}$ \\
\hline & $\begin{array}{l}\text { Características } \\
\text { do estudante }\end{array}$ & $\begin{array}{l}{[\ldots] \text { dependendo da dificuldade do aluno, da }} \\
\text { deficiência, precisa de um recurso maior, mais } \\
\text { textura, um recurso mais grosso }[\ldots] \text { (P5) }\end{array}$ \\
\hline
\end{tabular}

Fonte: banco de dados da pesquisa.

Elaboração dos autores. 
principalmente para que não ocorra a sua rejeição, pois o uso inadequado, sem periodicidade, não atinge o objetivo proposto, ocasionando desperdício de material, tempo e verbas investidas (Rocha, 2010).

Ainda que o momento inicial de avaliação do estudante em suas necessidades, capacidades e habilidades tenha ficado para trás, esse critério persiste durante todo o processo. Isso caracteriza a real necessidade de conhecer os estudantes para poder proporcionar algo que de fato contribua para a superação de obstáculos impostos pela deficiência.

Em síntese, é recorrente nas falas subscritas a incidência da avaliação dos estudantes, ao representar a ideia dos recursos pedagógicos. No entanto, outros dilemas cercam o tema, como a qualidade dos materiais, pensando em sua duração, modelo e segurança.

Ressalta-se também como um ponto crucial desse tema a opinião do estudante como um dos elementos indicadores no campo científico que apontam trabalhos que tematizam as causas de abandono da TA, no cenário nacional e internacional. Rocha (2010, p. 23) apresenta em seu trabalho uma discussão referente a esse processo de abandono,

Essas taxas elevadas de abandono da tecnologia assistiva sugerem que muitas pessoas estão insatisfeitas com seus recursos, o que resulta a suspensão de seu uso. $\mathrm{O}$ abandono desses recursos, além de deixar de beneficiar esses usuários, representa um desperdício de tempo e dinheiro para os profissionais, famílias e órgãos públicos.

Diante do exposto, identificam-se na prática dos professores importantes atitudes, como a abertura para o diálogo com os estudantes, familiares e outros profissionais e a preocupação de o recurso pedagógico não proporcionar aos estudantes preconceito e estigmatização no cotidiano do ensino comum.

\section{TEMA 5 - CONSTRUIR O OBJETO PARA EXPERIMENTAÇÃO}

Foi estabelecido como categoria desse tema apenas um elemento descritivo proposto no fluxograma:

1. experimentar na situação real de uso (Quadro 5).

Essa categoria revela a preocupação dos professores com a autonomia dos estudantes no uso dos recursos pedagógicos, para que, durante a sua utilização no ambiente de sala regular, este não possa causar conflitos, como a utilização do espaço comum, distração, bullying, entre outros.

Esse cuidado demonstra a complexidade que é a inserção do recurso pedagógico no cotidiano escolar do estudante, que não o utilizará apenas no AEE, mas na sala comum e, por vezes, em sua casa. Além de todo o processo para entender e escolher o recurso, surgem no cotidiano necessidades distintas, bem como habilidades e capacidades que se modificam com a superação de obstáculos.

As falas revelam que precede a apresentação e a exploração do objeto o conhecimento deste pelas pessoas que atuarão diretamente com o usuário, no que se refere ao seu objetivo e forma de manipulação. Apresentam ainda a invisibilidade do recurso pedagógico, conforme já mostrado anteriormente no tema 3 , situação em que o recurso passa despercebido, aproximando-se o máximo possível dos materiais utilizados pelos 
estudantes do ensino regular ou mesmo a quebra da estigmatização dos recursos ao apresentá-lo ao grupo em questão. Construir o objeto para experimentação também pode tirar a preocupação do professor no que se refere a desenvolver recursos adequados e suas adaptações, assim como a utilização na sala comum com o conhecimento do professor regular, segundo o currículo proposto para a turma.

Em síntese, evidencia-se por meio das falas dos participantes em relação à construção do objeto para a experimentação ser essa uma etapa cautelosa no processo do fluxograma, pois é o momento em que o professor especialista favorece a interação do recurso diante das expectativas e interesses dos estudantes e do professor regular. Pensar no recurso necessita refletir sobre essas experiências, a fim de que ela seja aceita tanto pelo estudante quanto pelo professor.

A partir das contingências relatadas pelos professores, observam-se condições intrínsecas ao que foi proposto pelo fluxograma na realização da adaptação e introdução do recurso no AEE e na sala regular. Apesar de o fluxograma contemplar diferentes etapas do processo de construção, aquisição e adaptação de recursos pedagógicos, os professores apresentaram de forma sistemática a introdução do recurso na rotina dos estudantes.

Quadro 5 - Construir o objeto para experimentação

\begin{tabular}{|c|c|c|}
\hline Categorias & Subcategorias & Extrato de falas \\
\hline \multirow{6}{*}{1} & $\begin{array}{l}\text { Questionar o estudante } \\
\text { sobre o que achou } \\
\text { do recurso }\end{array}$ & $\begin{array}{l}{[\ldots] \text { durante os atendimentos e durante as }} \\
\text { aulas, converso com as crianças [...] sobre } \\
\text { as experiências deles também do dia a dia, } \\
\text { vivência escolar, pessoal e da casa [...] (P1) }\end{array}$ \\
\hline & $\begin{array}{l}\text { Processo de adaptação } \\
\text { de recurso }\end{array}$ & $\begin{array}{l}\text { a gente aplica em sala de recurso e sala de aula regular, } \\
\text { então a agente verifica se alcançou sua funcionalidade; } \\
\text { caso não, a gente volta novamente o recurso e vamos } \\
\text { adequá-lo }[\ldots] \text { sempre que necessário }[\ldots](\mathrm{P} 4)\end{array}$ \\
\hline & $\begin{array}{c}\text { Explorar o objeto e } \\
\text { clareza nas informações }\end{array}$ & $\begin{array}{l}{[\ldots] \text { se as peças vão acabar chamando atenção }} \\
\text { e fazer com que eles acabem colocando na } \\
\text { boca, muitas vezes eles acabam mostrando para } \\
\text { gente na hora da aplicação, e a gente conclui: } \\
\text { "pensei que eles iriam gostar tanto" [...] (P2) }\end{array}$ \\
\hline & Clareza nas informações & $\begin{array}{l}\text { para que a criança entenda o que é para ser } \\
\text { feito, deve dar para uma pessoa comum as } \\
\text { atividades e ver se ela entende da mesma } \\
\text { forma que o aluno vai entender [...] (P2) }\end{array}$ \\
\hline & Invisibilidade do recurso & $\begin{array}{l}{[\ldots] \text { deixa a turma chegar perto, usar, olhar, }[\ldots]} \\
\text { deixei um jogo para todo mundo utilizar com ela, } \\
\text { depois eles perceberam que não era jogo }[\ldots](\mathrm{P} 3)\end{array}$ \\
\hline & $\begin{array}{l}\text { Onde e como } \\
\text { introduzir o recurso }\end{array}$ & $\begin{array}{l}\text { [...] eu penso naquele recurso tentando facilitar o } \\
\text { professor em sala de aula e a aprendizagem da criança } \\
{[\ldots] \text { mas antes eu faço tudo no AEE }[. . .] \text {, chamo }} \\
\text { a monitora para a sala e a observo utilizar, depois } \\
\text { chamo a professora para ver o atendimento [...] (P3) }\end{array}$ \\
\hline
\end{tabular}

Fonte: banco de dados da pesquisa.

Elaboração dos autores. 
Surgem, ainda, novas perspectivas diante dos recursos, destacando-se sua invisibilidade, que é uma das formas de superação do descarte de recursos apontados por Rocha (2010), pois o estudante sente-se bem em usar algo que se apresenta como natural em meio aos outros estudantes ou na sociedade como um todo.

Importante destacar a ocorrência da fala sobre a realização cautelosa de capacitação de monitores/estagiários e professores regulares para a utilização do recurso pedagógico na sala regular.

\section{TEMA 6 - AVALIAR O USO DO OBJETO}

Foram estabelecidos como categorias desse tema dois elementos descritivos propostos no fluxograma:

1. considerar se atendeu ao desejo da pessoa no contexto determinado; e

2. verificar se o objeto facilitou a ação do aluno e do educador (Quadro 6).

A categoria 1 revela que o professor se utiliza da avaliação inicial para pautar-se no desenvolvimento do estudante, partindo progressivamente para adaptações mais complexas, a fim de desenvolver as capacidades e habilidades inicialmente identificadas.

A categoria 2 revela em menor escala a realização do processo de avaliação dos recursos pedagógicos, destacando as necessidades do estudante para o recurso na sala regular. Da mesma forma, a participação dos professores especializados no cotidiano do estudante, que além de atenderem na SRM também realizam acompanhamentos nas salas regulares, ressalta a importância da disponibilidade do docente de forma contínua no ambiente escolar.

As falas revelam a subcategoria trabalho colaborativo como uma tendência em educação especial. Hoje, presente e difundida no cenário científico,

\begin{tabular}{|c|c|c|}
\hline \multicolumn{3}{|c|}{ Quadro 6-Avaliar o uso do objeto } \\
\hline Categorias & Subcategorias & Extrato de falas \\
\hline 1 & Atingir o interesse & $\begin{array}{l}\text { [...] um recurso totalmente adaptado, a gente tem } \\
\text { que aumentar esse nível de dificuldade [...] vai chegar } \\
\text { o momento em que ele não vai precisar mais de } \\
\text { adaptação, porque ela já atingiu o objetivo [...] (P2) }\end{array}$ \\
\hline \multirow{3}{*}{2} & $\begin{array}{c}\text { Processo de adaptação } \\
\text { e conhecimento } \\
\text { dos estudantes }\end{array}$ & $\begin{array}{l}{[\ldots] \text { a gente aplica em sala de recurso }} \\
\text { e sala de aula regular, é aí que a gente } \\
\text { verifica a funcionalidade [...] (P4) }\end{array}$ \\
\hline & Acompanhamento & $\begin{array}{l}{[\ldots] \text { Então, na avaliação diária, uso }} \\
\text { diário, uso diário mesmo [...] (P1) }\end{array}$ \\
\hline & $\begin{array}{c}\text { Trabalho colaborativo } \\
\text { e feedback do aluno }\end{array}$ & $\begin{array}{l}{[. . .] \text { sim, sempre do professor e da família, e às }} \\
\text { vezes até do coordenador pedagógico, eu falo assim: } \\
\text { "tudo que a gente decide hoje, por ser um trabalho } \\
\text { colaborativo, eu não decido sozinha" [...] (P3) }\end{array}$ \\
\hline
\end{tabular}

Fonte: banco de dados da pesquisa.

Elaboração dos autores. 
aparece de forma constante em pesquisas e congressos, no entanto, no interior das escolas, ainda possui uma abordagem tímida, porém presente no relato dos participantes.

Os relatos demonstram ainda que o tempo de desenvolvimento de cada estudante, quando alguns se desenvolvem mais rápido ou mais devagar, também pode ser um fator variável com uma deficiência que exige maior empenho, trabalho com equipes multidisciplinares, como o caso de estudantes com paralisia cerebral, que podem necessitar de fisioterapeuta, terapeuta ocupacional, neurologista, fonoaudiólogo, entre outros.

Resumidamente, por meio das falas dos participantes evidencia-se a avaliação do uso do recurso como algo fundamental para o processo do fluxograma, pois nesse momento surgem novos desafios para a utilização, bem como novas adaptações, modificações de materiais, dimensões etc.

A proposta do trabalho colaborativo como forma de avaliar o uso de recursos pedagógicos, partindo da premissa que tal parceria atua como uma estratégia perante o ensino, configura-se como um trabalho conjunto entre professores do ensino regular e especializado, garantindo assim melhores oportunidades de desenvolvimento.

\section{TEMA 7 - ACOMPANHAR O USO}

Foi estabelecido como categoria desse tema o elemento descritivo proposto no fluxograma:

1. verificar se as condições do aluno mudam com o passar do tempo e se há necessidade de fazer alguma adaptação no objeto (Quadro 7).

Essa categoria 1 revela diferentes aspectos do acompanhamento do uso do recurso, pautando-se ainda na avaliação e na importância de se capacitar todos os profissionais que atuam com o estudante para a utilização do recurso pedagógico, pois serão eles que irão realizar o acompanhamento no decorrer do ensino comum.

Resumidamente, o acompanhamento do uso do recurso pedagógico realizado pelos participantes aborda dois espaços: o AEE e a sala comum. Destacam-se como forma de acompanhamento diferentes momentos de observação dos estudantes no uso de recursos, tendo a colaboração como palavra-chave nessa instância de intervenção dos professores.

Quadro 7-Acompanhar o uso

\begin{tabular}{|l|c|c|}
\hline Categorias & Subcategorias & Extrato de falas \\
\hline \multirow{4}{*}{1} & Observar os estudantes & $\begin{array}{c}\text { [...] ser acompanhado em todos os momentos, deixar } \\
\text { alguns momentos da sua carga horária para você } \\
\text { assistir ao uso deles em sala regular, sempre combinado, } \\
\text { planejado com o professor do regular [...] (P4) }\end{array}$ \\
\cline { 2 - 3 } & Formação & $\begin{array}{c}{[\ldots] \text { primeiro eu levo para a minha sala a monitora, }} \\
\text { depois a professora e a família [...] (P3) }\end{array}$ \\
\hline
\end{tabular}

Fonte: banco de dados da pesquisa.

Elaboração dos autores. 


\section{CONSIDERAÇÕES FINAIS}

Os resultados obtidos permitiram compreender as diferentes ações do professor especializado no tocante ao desenvolvimento e aplicação dos recursos pedagógicos necessários aos estudantes da SRM. Isso responde aos propósitos deste trabalho quando se contingencia o fluxograma proposto por Manzini e Santos (2002) para avaliar recursos pedagógicos como escopo teórico e análise de conteúdo.

O estudo corrobora com diferentes proposituras de ações apresentadas nas subcategorias (desmembradas das categorias e pertencentes às sete etapas do fluxograma), o que implica concluir que os professores especialistas participantes deste estudo - e que são representativos de um vasto marco geográfico do estado de São Paulo - avançaram para além dos pontos que subsidiaram as temáticas do fluxograma, extrapolando para:

- emergir reiteradamente em diferentes formas e momentos a preocupação com a avaliação do estudante, permeada em todas as fases apresentadas no trabalho. Os relatos surgem em quatro diferentes temas, suscitando preocupação com as características pessoais e ambientais que cercam o estudante, antes e durante a utilização do recurso, até o momento em que as necessidades de adaptação se exaurem;

- a sistematização de introdução do recurso pedagógico da sala do AEE para a sala comum surge como destaque nos temas 5 e 6 . Essa transição da utilização do recurso nos dois ambientes (SRM e sala comum) apresenta-se como essencial para a compreensão, aceitação e adaptação do estudante ao uso do recurso;

- a preocupação com a invisibilidade do recurso pedagógico emerge nos temas 3 e 5 e adiciona-se às etapas propostas no fluxograma, atuando como um importante elemento para a aceitação pessoal e social do recurso pelo estudante, sobretudo no desenvolvimento dos objetivos propostos no recurso pedagógico. Destaca-se também como recorrente, nos temas 2, 4 e 5, a preocupação da utilização do recurso de TA na sala comum, com ênfase para as suas dimensões e características, a fim de torná-lo funcional e usual perante os estudantes da sala comum;

- a abordagem da colaboração entre diferentes profissionais ao desenvolver recursos de TA, como apresentado nos temas 2, 3 e 6 , ao abordarem orientações de utilização para o professor/monitor e um trabalho colaborativo constante entre os professores especializado e comum, bem como contar com uma equipe multidisciplinar e parceria com outros membros da escola;

- identificaram-se ações que versam diretamente com a manipulação do recurso de TA, desmembradas nos temas 1, 2, 3, 4 e 5, quando comparadas as preocupações dos participantes diante dos temas 6 e 7 .

Infere-se que os professores seguem o proposto no fluxograma, porém não o realizam na ordem sequencial determinada. Contudo, percebe-se pelos relatos que, antes de concluir a última etapa do fluxograma, recorrem às etapas 
anteriores a fim de melhor compreender a situação que os cercam, para adequá-las ao seu contexto.

Quanto ao desenvolvimento e aplicação dos recursos de TA em ambos os ambientes (SRM e sala comum), observou-se por meio da análise que a somatória do uso de um fluxograma de avaliação de TA adicionada à práxis dos professores especialistas proporciona novos indicativos na conjuntura de ações do professor diante das diferentes realidades e necessidades de seus estudantes.

\section{REFERÊNCIAS}

Alves, A. C.J. Tecnologia assistiva: identificação de modelos e proposição de um método de implementação de recursos. 2013. 145f. Tese (Doutorado em Educação Especial) — Universidade Federal de São Carlos, São Carlos, 2013.

Bardin, L. Análise de conteúdo. Tradução de Luís Antero Reta e Augusto Pinheiro. São Paulo: Edições 70, 2011.

Bersch, R. Tecnologia assistiva na educação inclusiva. In: ENSAIOS PEDAGógICOS. Brasília: Ministério da Educação, Secretaria de Educação Especial, 2006. p. 281-286. (II Seminário Nacional de Formação de Gestores e Educadores - Educação Inclusiva: direito a diversidade).

Brasil. Lei n. 9.394, de 20 de dezembro 1996. Estabelece as Diretrizes e Bases da Educação Nacional. Diário Oficial da União, Brasília, DF, 23 dez. 1996. Disponível em: <http://goo.gl/3YQoF>. Acesso em: 30 jun. 2015.

. Ministério da Educação. Portaria n. 13, de 24 de abril de 2007. Dispõe sobre a criação do Programa de Implantação de Salas de Recursos Multifuncionais. Diário Oficial da União, Brasília, DF, 26 abr. 2007. Disponível em: <http://goo.gl/cJmH0G>. Acesso em: 6 nov. 2015.

CAT - Comitê de Ajudas Técnicas. CAT, 5. 2007. Brasília. Ata de Reunião... Brasília: CAT, CORDE; SEDH, 2007.

Соoк, A.M.; Polgar,J. M. Cook E Hussey's assistive technologies: principles and practices. 3rd. St. Louis: Mosby Elsevier, 2008.

Cruz, D. M. C.; Ioshimoto, M. T. A. Tecnologia assistiva para as atividades de vida diária na tetraplegia completa C6 pós-lesão medular. Revista Triângulo, Uberaba: Universidade Federal do Triângulo Mineiro, v. 3, n. 2, p. 177-190, 2010.

Deliberato, D. Seleção, adequação e implementação de recursos alternativos e/ou suplementares de comunicação. In: Pinho, S. Z.; Saglietti, J. R. C. (Orgs.). Núcleos de ensino da UNESP, São Paulo: UNESP, v. 1, p. 505-519, 2005. Disponível em: <https:// goo.g1/qJuhNB>. Acesso em: 18 dez. 2017.

Galvão Filho, T. A. Tecnologia assistiva: favorecendo o desenvolvimento e a aprendizagem em contextos educacionais inclusivos. In: Giroto, C. R. M.; PокеR, R. B.; Омоте, S. (Orgs.). As tecnologias nas práticas pedagógicas inclusivas. Marília: Oficina Universitária; São Paulo: Cultura Acadêmica, 2012. p. 65-92. Disponível em: <https:// goo.gl/Ja71me>. Acesso em: 31 out. 2015. 
Galvão Filho, T. A.; Miranda, T. G. Tecnologia assistiva e paradigmas educacionais: percepção e prática dos professores. In: Reunião Anual da Associação Nacional de Pós-Graduação e Pesquisa em Educação,34.,2011, Natal.Anais... Natal:ANPEd, 2011.

Giroto, C. R.M.; Рокеr, R. B.; Омоте, S. Educação especial,formação de professores e o uso das tecnologias de informação e comunicação: a construção de práticas pedagógicas inclusivas. In: Giroto, C. R.M.; Рокеr, R. B.; Омоте, S. (Orgs.). As tecnologias nas práticas pedagógicas inclusivas. Marilia: Oficina Universitária; São Paulo: Cultura Acadêmica, 2012. p. 11-24. Disponível em: <https://goo.gl/Ja71me>. Acesso em: 31 out. 2015.

Gonçalves, A. G. Desempenho motor de alunos com paralisia cerebral frente à adaptação de recursos pedagógicos. 2010. 166f. Tese (Doutorado em Educação) - Faculdade de Filosofa e Ciências, Universidade Estadual Paulista, Marília, 2010.

ITS Brasil - Instituto de Tecnologia Social Brasil. Portal Nacional de Tecnologia Assistiva: Catálogo. São Paulo: ITS Brasil, 2014. Blog dedicado a divulgar entre outras coisas, o Catálogo Nacional de Produtos de Tecnologia Assistiva. Disponível em: $<$ https://goo.g1/8pCAUA>. Acesso em: 19 dez. 2017.

Judge, S.; Floyd, K.; JefFs, T. Usin na assistive technology toolkit to promote inclusion. Early Childhood Educ Journal, Netherlands: Springer, v. 36, n. 2, p. 121-126, June 2008. Disponível em: <http://goo.gl/uVgwbt>. Acesso em: 31 out. 2015.

Lourenço, G. F.; Mendes, E. G. Proposta preliminar de etapas para a implementação de recursos de alta tecnologia assistiva com alunos com paralisia cerebral. In: Congresso Brasileiro de Educação Especial, 5.,2012, São Carlos.Anais... São Carlos:UFSCar,2012. Manzini, E. J. Considerações sobre a elaboração de roteiro para entrevista semiestruturada. In: Marquezine, M. C.; Almeida, M. A.; Omote, S. (Orgs.). Colóquios sobre pesquisa em educação especial. Londrina: Eduel, 2003. p. 11-25.

. Entrevista semiestruturada: análise de objetivos e de roteiros. In: SEMINÁrio Internacional de Pesquisa e Estudos Qualitativos, 2., 2004, Bauru. A pesquisa qualitativa em debate. Anais... Bauru: USC, 2004.

. Consideraçôes sobre a transcrição de entrevistas. [S.1.: s.n.], [2012]. Disponível em: <https://goo.g1/nfzFzG>. Acesso em: 19 dez. 2017.

. Possíveis variáveis para estudar as salas de recursos multifuncionais. In: JEsus, D. M.; Baptista, C. R.; Caiado, K. R. M. (Orgs.). Prática pedagógica na educação especial: multiplicidade no atendimento educacional especializado. Araraquara: Junqueira \& Marin, 2013.p. 114-129.

Manzini, E. J.; Santos, M. C. F. Portal de ajudas técnicas para a educação: equipamento e material pedagógico para educação, capacitação e recreação da pessoa com deficiência — recursos pedagógicos adaptados. 1. ed. Brasília: MEC, 2002. v. 1.

Marconi, M. A.; Lakatos, E. M. Fundamentos de metodologia cientifica. 7. ed. São Paulo: Atlas, 2010.

Melchiori, L. E.; Rodrigues, O. P. R.; Maia, A. C. B. Escola e família: uma parceria possível e necessária. São Paulo: Acervo Digital da UNESP/REDEFOR II/NEaD/ UNESP, 2014. Acesso restrito. Disponível em: <http://acervodigital.unesp.br/handle/ unesp/155265 >. Acesso em: 31 out. 2015. 
Miranda, T. G.; Galvão Filho, T. A. Tecnologia assistiva de salas de recursos: análise crítica de um modelo. In: Miranda, T. G.; Galvão Filho, T. A. (Orgs.). O professor e a educação inclusiva: formação, práticas e lugares. Salvador: EDUFBA, 2012. p. 247-266.

Oliveira, A. A. S. Da avaliação ao planejamento: foco na ação do professor especializado. São Paulo: NEaD; UNESP, 2014. Texto utilizado na disciplina 11 do curso de especialização em educação especial na área de deficiência física do Programa Rede São Paulo de Formação Docente. Disponível em: <http://goo.gl/RyazQu>. Acesso em: 31 out. 2015.

Preti, D.; Urbano, H. (Orgs.). A linguagem falada culta na cidade de São Paulo. São Paulo: T. A. Queiroz; FAPESP, 1990. (Estudos, v. 4).

Queiroz, F. M.M. G. Tecnologia assistiva e perfil funcional dos alunos com deficiência física nas salas de recursos multifuncionais. 2015.117f. Dissertação (Mestrado em Educação) Universidade Estadual "Júlio de Mesquita Filho", Faculdade de Filosofia e Ciências, Marília, 2015.

Rocha, A. N. D. C. Processo de prescrição e confeç̧ão de recursos de tecnologia assistiva para educação infantil. 2010. 199f. Dissertação (Mestrado em Educação) - Universidade Estadual Paulista "Júlio de Mesquita Filho", Marília, 2010. Disponível em: <https:// goo.gl/LICLyH >. Acesso em: 31 out. 2015.

Rocha, A. N. D. C.; Deliberato, D. Tecnologia assistiva para a criança com paralisia cerebral na escola: identificação das necessidades. Revista Brasileira de Educação Especial, Marília: ABPEE, v. 18, n. 1, p. 71- 92, jan./mar. 2012. Disponível em: <http://goo.g1/ g8Pwtf $>$. Acesso em: 31 out. 2015.

Rodrigues, L. M. B. C. Tecnologia assistiva no processo de inclusão da pessoa com deficiência na rede pública de ensino. 2013. 125f. Dissertação (Mestrado em Psicologia do Desenvolvimento e Aprendizagem) - Universidade Estadual Paulista "Júlio de Mesquita Filho", Faculdade de Ciências, Bauru, 2013.

Rodrigues, L. M. B. C.; Capellini, V.L. M.F. O acesso dos professores especialistas aos recursos de tecnologia assistiva na rede municipal e estadual. In: Congresso Brasileiro de Educação, 3., 2011, Bauru. Anais... Bauru: UNESP, 2011. Disponível em: <http://www2.fc.unesp.br/cbe/iii_cbe/index.htm>. Acesso em: 6 set. 2011.

SANKaKo, A. N.; Braccialli, L. M. P. Tecnologia assistiva para facilitar o acesso motor da criança com paralisia cerebral. In: Oliveira, J. P.; Cruz, G. C.; Miura, R. K. K.; Mello, P. M.; Oliveira, R. T. O. (Orgs.). Perspectivas e contribuições da educação especial para a inclusão escolar. 1. ed. Curitiba: CRV, 2014. p. 67-78.

Sartoretto, M. L.; Bersch, R. A educação especial na perspectiva da inclusão escolar: recursos pedagógicos acessíveis e comunicação aumentativa e alternativa. Brasília: Ministério da Educação, Secretaria de Educação Especial; [Fortaleza]: Universidade Federal do Ceará, 2010.

Schlünzen, E. T. M. et al. Ambientes potencializadores para inclusão e núcleo de ensino. Caderno de Formação: formação de professores, didática geral, São Paulo: Cultura Acadêmica; Universidade Estadual Paulista; Pró-Reitoria de Graduação, v. 21, p. 15-31, 2011. 
Silva, M. O. Protocolo para prescrição ou adaptação de recursos pedagógicos para alunos com paralisia cerebral. 2010. 195f. Dissertação (Mestrado em Educação) - Universidade Estadual Paulista "Júlio de Mesquita Filho", Faculdade de Filosofa e Ciências, Marília, 2010. Disponível em: <https://goo.gl/PCdJak>. Acesso em: 11 nov. 2015.

Urban, A. L. P.; Mendes, E. G. Os recursos de tecnologia assistiva que têm sido utilizados por alunos com a paralisia cerebral em município do interior paulista. In: Congresso Brasileiro de Educação Especial, 5., 2012, São Carlos. Anais... São Carlos: UFSCar, 2012. p. 6.923-6.935. 1 CD-ROM.

Verussa, E. O. Tecnologia assistiva para o ensino de alunos com deficiência: um estudo com professores do ensino fundamental. 2009.96f. Dissertação (Mestrado em Educação) Universidade Estadual Paulista, Faculdade de Filosofia e Ciências, Marília, 2009. Disponível em: <https://goo.gl/hFKALM>. Acesso em: 31 out. 15.

\section{SOBRE OS AUTORES}

Manoel Osmar Seabra Junior é doutor em educação pela Universidade Estadual Paulista (UNESP). Professor da mesma instituição.

E-mail: seabrajr.unesp@gmail.com

Lonise Caroline Zengo de Lacerda é mestranda em educação pela Universidade Estadual Paulista (UNESP).

E-mail: lonisezengo@hotmail.com

Recebido em 16 de novembro de 2015 Aprovado em 25 de abril de 2016 